\title{
Measures to improve the effectiveness of the training for new police officers -with a focus on Central Police Academy
}

\author{
Sungmin Bang, Changho Kim* \\ Dept. of Security Management, Kyonggi University, Suwon, Korea
}

\section{Email address:}

kch@kgu.ac.kr (C. Kim)

\section{To cite this article:}

Sungmin Bang, Changho Kim. Measures to Improve the Effectiveness of the Training for New Police Officers -With a Focus on Central Police Academy. Humanities and Social Sciences. Vol. 2, No. 6, 2014, pp. 139-142. doi: 10.11648/j.hss.20140206.11

\begin{abstract}
Training programs for police officers provide necessary knowledge and skills for fulfilling daily tasks. Moreover, the moral aspect of the training instills discipline in the recipients to function as volunteers for the citizens. Therefore, it is the starting point for the new officers to not only achieve their individual goals, but to contribute to the organizational aim. Unfortunately, the training provided at the Central Police Academy (CPA) in South Korea suffers from the overwhelming amount of courses provided to the trainees over a short period of time and an overemphasis on the theoretical aspects of work. In this study, current states of the training in the United Kingdom and the United States are reviewed. A couple of things to note in the US system is that the content of training is becoming more diverse and the training period is being extended. Furthermore, it is a military-style training. A unique characteristic of the UK training is that it has employed the "apprenticeship" system. This study discusses issues with the training for new police officers in South Korea by examining comparable aspects in the United States and the United Kingdom. Extension of training period, practice-oriented education, and benchmarking the apprenticeship-based program in the United Kingdom are suggested. Additionally, assessing individual characteristics thoroughly at the school is recommended in order to increase the overall outcome of the police work.
\end{abstract}

Keywords: Public Security Training Institute, Police Officer, New Officer, Training Program, Central Police Academy

\section{Introduction}

In the rapidly changing and the complex environment, the police has strived to produce quality workforce. Also, raised civil awareness demands high-quality security work from the police. To fulfill the increasing demand, newly hired officers and inspector-level officers are trained at the Central Police Academy (CPA and the Police Training Institute and the Korea National Police University (KNPU), respectively.

Nonetheless, the length (i.e. 34 weeks for new officers, 52 weeks for cadets, and 48 months for the KNPU students) and depth of the training are considered insufficient to provide the necessary training. Since the police officers comprise $82.4 \%$ of the lower-rank officers, the training targeting them must be emphasized.

Therefore, this study explores ways to increase the quality of training that to provide adequate lessons and help raise the officers' awareness for working properly as public servants. In addition, the suitability of the training period is reviewed as a measure to improve the current training system for new police officers. Specifically, this article aims to tackle the issue of the short period of training which affects the quality of lessons. Also, ways to improve the related human and resource infrastructure are discussed.

In the current research, face-to-face interviews were carried out with new police officers who were under training at the Central Police Academy (CPA). The interviews were conducted from March to May 2014, and each semi-structured interview lasted for one and half hour on average. Additional phone calls were made when there was a need to clarify the information provided. As the interviews were conducted, it became evident from the tenth subject onward that similar content was being discussed repetitively, which made continuing the interviews unnecessary. The final number of interview participants was fifteen. During the interview, focus was placed on the effectiveness of the training programs for new police officers. 


\section{Literature Review}

\subsection{Definition of Police Education Training}

Police education training refers to the effort invested by the national agency to provide opportunities for the officers to gain the knowledge and techniques needed for their work and develop their values and attitudes [1]. Therefore, the police training helps individual officer contribute to the organizational goal achievement in a democratic and an efficient way.

\subsection{The Relationship between Police Training and Learning Period}

Some scholars argue that the learning period should be perceived as one of the finals steps before actual hiring of an individual [2]. To illustrate, this is a good opportunity to asses' individual competence in carrying out the necessary tasks. This method is also used in other professional fields including medicine, law, and academia.

According to scholars, the learning period before getting into actual work should at least be one year to reap the benefits [2]. Unfortunately, the learning period in the Korean context is little more than its mere presence without the systematic implementation.

\subsection{Discussion of the Effectiveness of the Training for New Officers}

\subsubsection{Components of Police Training}

Instructor, student, training environment, and training stage comprise police training. In order for police educational training to be successful, each component must maintain its normal functions [3]. Instructors convey messages and knowledge and even acts as the mediators who can transform the students' behavior and characteristics. Students are expected to be multi-specialists in this fast-changing era. specifically, well-rounded individuals are well suited for the dynamic work environments of the police organization. Moreover, the tools and resources must be updated and available to facilitate the learning experience. Finally, different aspects of the police work that are crucial in performing daily work are included in the training sessions.

\subsubsection{Factors of Training Satisfaction}

Satisfaction level of training is affected by diverse factors including human, physical, and psychological correlates. Training satisfaction increases the efficiency of the training and affects the educational performance directly and indirectly [4]. The factors of educational training can be categorized into external and internal factors. External factors are related to individuals and internal factors that are related to the school and the instructors [4], suggests that training satisfaction can be classified into the training design, operation, and content [5].

\section{Characteristics of the Training for Newly Hired Officers in the United States and the United Kingdom}

\subsection{Training System for New Police Officers in the United States}

The specific length and content of training vary by state an training institution. However, one common trend is that the material covered in the training programs is becoming more diverse and the length of training is extended. In this study, the case of Los Angeles Police Department (LAPD) is examined.

First, individuals who have passed the entry examination go through the eight-month long intensive training at the LAPD Police Academy. The trainees get paid for their participation. In addition to the education provided in class related to the laws, interpersonal relationship, foreign language, report writing, etc., outdoor training such as self-defense, shooting, and driving, ect is included. Specifically, physical training and self-defense are an important part of the program. Because of the high-level intensity, the trainees are recommended to review the process and prepare themselves for it.

Following is the detailed description of the training system at LAPD.

First, 230 hours of training is required on arrest and report, investigation, wireless communication, report writing, traffic accident investigation, enforcing traffic-related laws, etc.

Second, 40 hours of training is included for defensive driving and other driving strategies in cases of emergency.

Third, 113 hours of firearms training includes safe handling and storing firearms, marksmanship, carrying firearms, and methods to handling chemical substances.

Fourth, 100 hours of training is provided on human relations, including maintaining positive relationships with the media, stress management, effective communication, hate crime, missing person cases, and domestic violence.

Fifth, 105 hours of training is related to different laws on confiscation, evidence collection, arrest, and sex crime and crime against minors.

Sixth, 142 hours of physical training aimed to promote the maintenance of healthy bodies, positive mind set, and endurance is provided. In this part of the training, self-defense is covered. As the statistics show, more than 100 officers die at workplace and about 40,000 officers are attacked by offenders; so this part of the training is highly emphasized. Police officers usually work independently from each other but team work is still emphasized [6].

Seventh, tactics training teaches the trainees about patrol strategies, making arrests at the crime scene, checkpoint searches, how to use fatal weapons and their limitations over the course of 98 hours.

Eighth, the LAPD Specific Training includes high-level strategic techniques, special strike strategies, usage of the computers installed in vehicles, regulations on alcohol addiction and other work-related matters, cultural diversity 
training, usage of K-9, air force back up plans, disassembling bomb, etc. [7].

As described above, the focus of the LAPD training is simulation of actual work setting and it is carried out in a manner that is similar with military training. Despite the fact that the police organization is citizen-oriented, the officers receive military style training owing to the characteristics of their work, so private and individual opinions are often ignored [8]. [9].

\subsection{Training System for New Police Officers in the United Kingdom}

The training system in the United Kingdom has been implemented for a long time and it is a useful method to sort out the individuals who might not be suitable to accomplish their duties despite the fact that they have passed the entry exams. In addition, it is meaningful because it is a good opportunity for the individuals to self-examine and self-discipline [9].

The IPLDP emphasizes the development of curricula. The point here is that the supervising agency is responsible for the trainees at the base level and higher level agencies are in charge of training and managing police officers and operating the training system.

Particularly, the previous model with six stages are transformed by the national occupation standard and learning demand model and are adjusted to the individual learning style, effort, past experience, certificates, and intrinsic attitude and behavior. The 23 items of the standard comprised the 22 models which are again categorized into four stages. The first three stages are the independent components and are fulfilled before actual patrol work.

Stage-1: 3-5 weeks of introduction courses given at local agencies. They include emergency situation management, risk management, hygiene and safety education, ethnicity and diversity, professional standard, usage of fundamental techniques, and local issues. Individuals are sworn in and the official authority is given to them.

Stage 2: Community safety and training on public safety (2-3 weeks of training in which the trainees learn about related laws, ways to respond to and participate in solving the local crime problems, and are dispatched using risk evaluation. In this process, constant communication is necessary between supervisors.

Stage 3-Patrol under supervision (flexible programs about laws, policies, and guidelines that vary by location). From this point, officers create the crime investigation models of IPLDP version and select courses. Until they finish every training, the trainees learn about the investigation processes and acquire necessary skills. Also, case file writing and management are included. To help increase suitable responses in real-life situations, trainers and supervisors try to simulate real-life environments even in indoor training sessions.

Stage 4-Independent patrol (trainees go through about 30 days of supervised patrol first). In addition, in-class training that is required and that is optional are provided separately.
Trainees give presentations on training performance which is assessed by an evaluator. The evaluation process follows the National Occupational Standard (NOS).

If proof of course fulfillment for any of the training described above is submitted, the trainee can obtain waiver for the course. Moreover, in the case in which there are no instructors available, other authorized agencies can provide the training. In this case, the training hours can be transferred for college or graduate school credits or approved as the level 3 National Vocational Qualification (NVQ) [10].

Furthermore, for the smooth process of IPLDP, the National Centre for Applied Learning Technologies (NCALT) is in the process of developing a program.

\section{Improvement Measures for Training of New Officers}

\subsection{Extension of Training and Enhancing the Training System}

Much discussion has been focused on the need to extend the length of training. Also, the system that produces the officers who are ready to work in real-life situations and promotes work ethics must be implemented.

\subsubsection{Increasing Capability of Instructors}

Capable instructors are an important part of effective training. One-on-one training and mentor system will be helpful and providing coaching and feedback for presentation is also suggested for the change.

\subsubsection{Reinforcement of Moral Education}

The moral of individual officers is very important because they will have direct interactions with the citizens. Texts that are aligned with the goal of establishing appropriate moral and ethics should be prepared and mentor system and counseling should be provided continually. Additionally, the trainees that need special attention must be managed separately to maximize their training outcomes.

\subsubsection{Establishment of Comprehensive Real-Life Practice Town to Improve Adjustment to Actual Situations}

Police officers' work must be specialized because the police activities place a great emphasis on the interaction between citizens and the police. Therefore, a place where the officers can reenact, review, and practice what they have learned will increase the applicability of their training to real-life situations.

\section{Conclusions}

Compared to the training for new police officers in advanced countries, the training in Korea has been considered ineffective due to its short period. Specifically, the lack of applicability to real-life situations, inability of the training to sort out unsuitable individuals, the lack of emphasis on moral education have been pointed out as main weaknesses. Also, the problem with the legal status of the 
trainees and inappropriate training environments have contributed to the low training satisfaction level.

Developing diverse teaching methods and moral education programs must be considered to increase the work ethics and moral of new police officers. Furthermore, the training before actual employment and new employee training must happen concurrently to increase the quality of training and improve the morale of the officers. Moreover, quality education provided by capable instructors is an important part of the improvement plan. Lastly, reasonable and wise distribution of resources should be the basic premise of the change.

Improving the training and education programs for new officers must be viewed from a broad perspective since it will affect the future of the police organization. Currently, each government sector is going through its own issues but the problem of the training provided at CPA must be addressed comprehensively.

With more number of quality officers being added to the organization, the quality of the instructors must improve as well. One way to accomplish this goal is to improve the pay and benefits for the instructors, which can work as a motivating factor and draw more qualified personnel to do the job. Nonetheless the most important thing is to reduce the amount of teaching load so the instructors have enough time to prepare their lectures and study the relevant material before each lesson.

\section{References}

[1] H. Lee and B. Jo and E. Choi, "Introduction to Police Administration", Korea Institute of Criminology, 2006.

[2] Fyfe, J. James and R. Greene and Walsh and F. William and Wilson and O. W., \& McLaren and Roy Clinton., Police Administration(5th ed.), New York: The McGraw-Hill Companies, Inc pp.309-310,1997

[3] H. Lee, "Police Administration", Seoul: Bupmunsa, 2007.

[4] E. Han, "An Analysis of Academic station of Provincial College education", 23(3 ):pp. 379-399, 2003

[5] M. Kim, "Training of local officials Satisfaction Implications and Challenges" 18(2):pp. 21-40,2007

[6] I Ienno "Studv in Snuth Korea police education and training systems"6: pp.7-27,1995

[7] M. Kim, "A Study on Improving the Police Training System of Police Cadets at the National Central Police Academy”.2008

[8] Westley, "study of professional and organizational learning in schools", 1990

[9] J. Jung, "Privatization and New Directions in the study of Policing", 2006.

[10] H. Park, "A Study on the Improvement of the Korean Local Police Service in the Era of Municipal Policing”, 2007. 